\title{
Support of Cultured Hepatocytes by a Laminin-rich Gel Evidence for a Functionally Significant Subendothelial Matrix in Normal Rat Liver
}

\author{
D. Montgomery Bissell, David M. Arenson, Jacqueline J. Maher, and F. Joseph Roll \\ The Liver Core Center and Medical Service, San Francisco General Hospital, and Department of Medicine, \\ University of California, San Francisco, California 94143
}

\begin{abstract}
The subendothelial space of normal rat liver contains the constituent proteins of a basal lamina, as judged by immunohistochemical study of tissue sections. However, it is unknown whether these proteins constitute a complex with effects on hepatocellular function. We have examined this question, using normal rat hepatocytes cultured on substrata of matrix proteins as a model of the interaction between cells and basal lamina in vivo. In cultures on a type I collagen substratum, albumin secretion decreased progressively after $2 \mathrm{~d}$. By contrast, when cells were cultured on a laminin-rich gel matrix, albumin secretion was stable for at least $3 \mathrm{wk}$; other functions and ultrastructural morphology were similarly maintained. None of the individual matrix proteins effectively substituted for the gel matrix, suggesting that full support of hepatocellular function requires a complex of matrix proteins. We speculate that a cause of hepatocellular dysfunction in acute inflammation is disruption of this matrix and alteration of its interaction with the hepatocyte plasma membrane.
\end{abstract}

\section{Introduction}

The extracellular matrix of many, if not all, epithelia is similar in composition, consisting largely of laminin, type IV collagen, and heparan sulfate proteoglycan $(1,2)$ and is organized as a discrete layer, or basal lamina, abutting the antisecretory face of the epithelial cell. Recent studies suggest that the basal lamina provides not only structural support but also binding sites for epithelial cells and indirectly may determine the level of expression of tissue-specific functions. Morphogenesis appears to require the presence of extracellular matrix (reviewed by Wessels [3] and Hay [4]). Similarly, sustained expression of differentiated functions by mature epithelial cells in primary culture may depend critically on the presence of matrix proteins $(5,6)$, suggesting that the basal lamina, far from being only a passive support, has specific metabolic effects on the tissue epithelium.

Extension of this concept to the liver has been problematic. Morphologic techniques fail to show a basal lamina in this tissue. At least in young rat liver, electron microscopy fails to reveal a structure identifiable as such at the basal surface (the sinusoidal

A preliminary report of this work appeared in abstract form (1985. Hepatology. 5:1038).

Address correspondence to Dr. D. M. Bissell, Liver Center Laboratory, Building 40, Room 4102, San Francisco General Hospital, San Francisco, CA 94110. 1986.

Received for publication 20 May 1986 and in revised form 27 October

J. Clin. Invest.

(c) The American Society for Clinical Investigation, Inc.

$0021-9738 / 87 / 03 / 0801 / 12 \$ 1.00$

Volume 79, March 1987, 801-812 face) of hepatocytes. Indeed, this area-the subendothelial (Disse) space-appears devoid of structures other than the protruding microvilli of hepatocytes. The recent development, however, of specific antibodies to individual components of the basal lamina, combined with the high sensitivity afforded by fluorescence microscopy, has provided evidence that the subendothelial space of normal liver contains type IV collagen and heparan sulfate proteoglycan $(7,8)$. Fibronectin also is present but may not be integral to the basal lamina, representing rather the plasma form of the protein secondarily associated with the matrix $(9,10)$. The presence of laminin is disputed $(7,11,12)$. Recent studies from this laboratory demonstrate laminin in the subendothelial space of normal liver and suggest that a perisinusoidal cell, the lipocyte, produces it $(13,14)$.

While the appropriate individual proteins appear to be present at the basal surface of hepatocytes, it remains unclear whether or not these act as a complex and are functionally significant. Primary hepatocyte culture provides a direct test of this question. Freshly isolated cells, plated in a complete culture medium, reconstitute many of the features of the liver in vivo, including intercellular structures that resemble canaliculi both morphologically (15) and functionally (16). The basolateral surface of individual cells attaches to the culture substratum, modeling the interaction of hepatocytes and basal lamina in the intact tissue. The culture system permits controlled manipulation of the substratum, with direct measurement of the cellular response. Using this model, we have examined the ability of matrix proteins, singly or as a complex, to support hepatocellular function. The results indicate that a laminin-rich gel matrix is strikingly superior to individual basal lamina constituents in this regard. We conclude that the composition and structure of the subendothelial matrix are major determinants of normal liver function.

\section{Methods}

Immunochemical methods. Salt-soluble type I and III collagen were isolated from the skin of Sprague-Dawley rats made lathyritic by addition of $0.1 \%$ beta-aminopropionitrile (BAPN) ${ }^{1}$ to their drinking water. The collagens were purified by repeated salt precipitation as described by Trelstad et al. (17). Purity was assessed by SDS polyacrylamide gel electrophoresis (PAGE) of the individual collagens and by amino acid analysis. Antisera to the collagens were raised in rabbits and affinity-purified as previously described (18). The final antibodies had titers of 1:25,600 (type I) and 1:12,800 (type III), and each showed no cross reactivity with the other or with type IV collagen by competition enzyme-linked immunosorbent assay (ELISA) performed as described $(19,20)$.

Other matrix components (laminin, type IV collagen, and heparan sulfate proteoglycan) were isolated from the Engelbreth-Holm-Swarm (EHS) tumor (21), which was maintained in this laboratory in SwissWebster mice made lathyritic by addition of $0.1 \%$ BAPN to the drinking water. Laminin was isolated by the methods of Timpl et al. (22) and Kleinman et al. (23). In brief, the tumor was homogenized in $3.4 \mathrm{M}$

1. Abbreviations used in this paper: BAPN, beta-aminopropionitrile; EHS, Engelbreth-Holm-Swarm. 
$\mathrm{NaCl}$ and $0.05 \mathrm{M}$ Tris ( $\mathrm{pH} 7.4$ ) containing the following protease inhibitors: $1 \mathrm{mM}$ diisopropyfluorophosphate, $1 \mathrm{mM} N$-ethylmaleimide, and $50 \mu \mathrm{g} / \mathrm{ml}$ phenylmethanesulfonic acid. After centrifugation $(13,000 \mathrm{~g}$ for $30 \mathrm{~min}$ ) the pellet was washed five times with the same buffer. The final pellet was extracted first with $1.7 \mathrm{M} \mathrm{NaCl}$ and $0.05 \mathrm{M}$ Tris- $\mathrm{HCl}(\mathrm{pH}$ 7.4), and then with $2 \mathrm{M}$ guanidine and $0.05 \mathrm{M}$ Tris- $\mathrm{HCl}$ (pH 7.4) (both supplemented with protease inhibitors). The two supernates containing crude laminin were combined, dialyzed against $2 \mathrm{M}$ urea, $0.05 \mathrm{M}$ Tris, and $0.25 \mathrm{M} \mathrm{NaCl}$ (pH 8.6) and passed over a DEAE (DE-52; Whatman Chemical Separation Inc., Clifton, NJ) column and eluted with the same buffer. Initially unbound material, which on SDS PAGE consisted of $\sim 90 \%$ laminin A and B chains and $10 \%$ a single band having the molecular mass (150-160 kD) of entactin, was treated in two ways. (a) The DEAE-purified laminin was electrophoresed on nonreducing $3.5 \%$ preparative SDS gels, and the band corresponding to intact laminin $(\sim 800$
$\mathrm{kD}$ ) was cut from the gel and the protein eluted with $0.2 \mathrm{M}$ ammonium bicarbonate ( $\mathrm{pH} \mathrm{8.6).} \mathrm{SDS} \mathrm{PAGE} \mathrm{of} \mathrm{this} \mathrm{material} \mathrm{under} \mathrm{reducing} \mathrm{con-}$ ditions revealed only laminin A and B chains. SDS was removed from the protein by dialysis against ethanol, and the laminin was used for immunization of rabbits by published schedules (24). (b) The $P_{1}$ fragment of laminin - the disulfide-bonded central portion of the molecule that contains most of the antigenic sites of the intact molecule-was prepared by pepsin digestion of the DEAE-purified laminin (24) and chromatography on $\mathrm{A} 1.5 \mathrm{~m}$ agarose. The peak eluting in the void volume of this column consisted of a single protein band, identified by molecular size $(280 \mathrm{kD})$ as the $P_{1}$ fragment with no detectable entactin. This material was used to prepare an affinity column.

The anti-sera raised to these laminin preparations were purified by absorption and elution from the $P_{1}$-fragment affinity column. The final anti- $P_{1}$ antibody had a titer of $\sim 1: 10,000$ against $P_{1}$ and 1:10,000 against
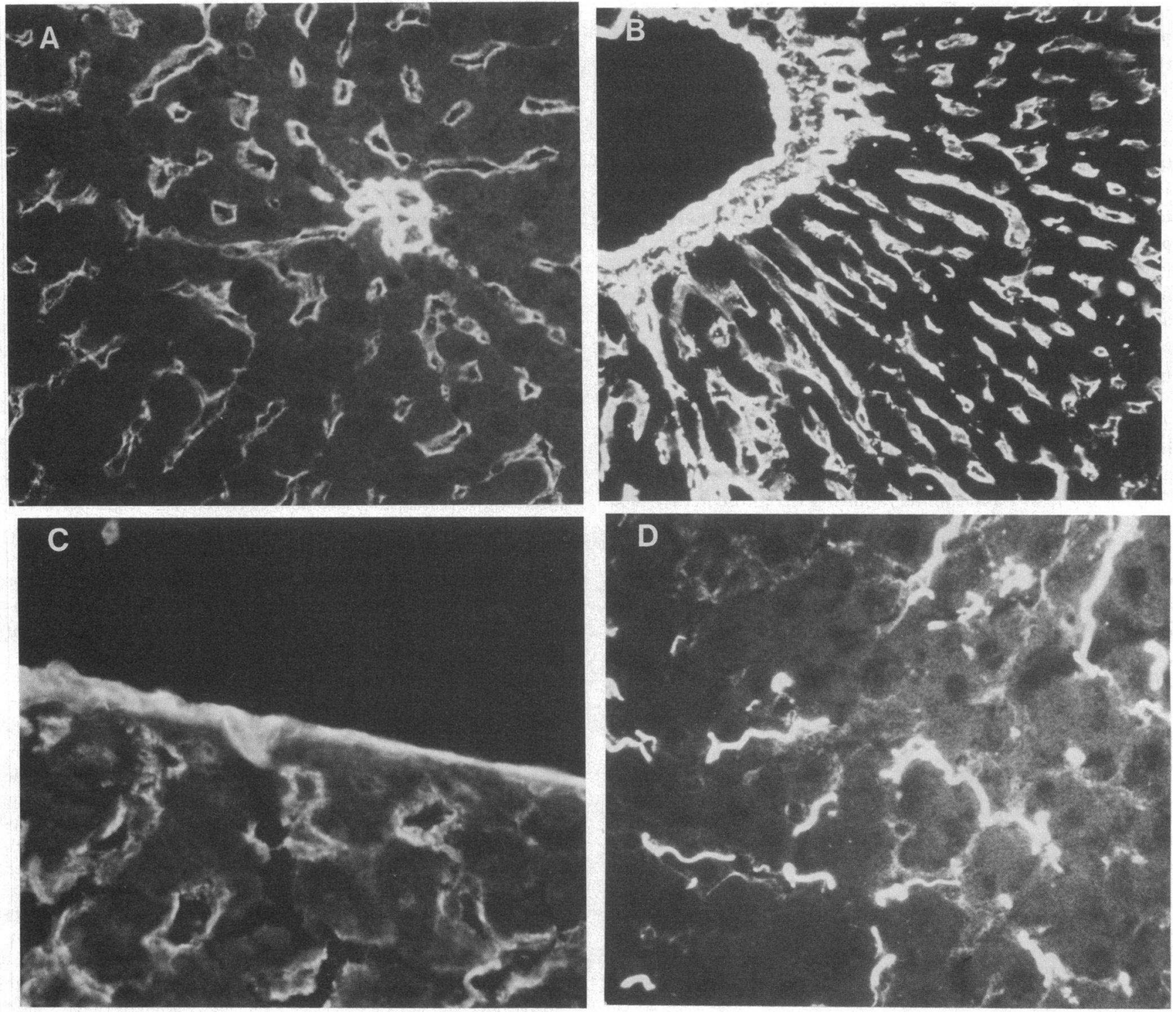

Figure 1. Localization of basal lamina collagen and glycoproteins in normal rat liver. Frozen sections of liver were prepared and stained as outlined in Methods, with affinity-purified antibodies to laminin $(A)$, type IV collagen $(B)$, fibronectin $(C)$, and type I collagen $(D)$. The secondary antibodies were fluorescein-conjugated $(A$ and $C)$ or rhodamine-conjugated $(B$ and $D$ ). The photomicrographs show a sinusoidal

distribution for laminin, type IV collagen, and fibronectin, in addition to their deposition around central veins. By contrast, antibody to type I collagen $(D)$ reveals within the lobule a few thick fibrils only; staining for type III collagen was similar (not shown). ( $A, C$ and $D, \times 700 ; B$, $\times 350$ ). 
whole laminin by ELISA; by immunoblot, it reacted with laminin A and $B$ chains but showed no cross reactivity with type I or type IV collagen. Inhibition ELISA curves using $P_{1}$ and intact laminin, respectively, to inhibit anti- $P_{1}$ were parallel as described by Rohde et al. (24), indicating that the same antigen was recognized by the antibody. This antibody was used for the immunofluorescence and ELISA studies. Later in the course of the work, laminin taken through the DEAE step was further purified by chromatography on another DEAE column equilibrated with $2 \mathrm{M}$ urea and $0.05 \mathrm{M}$ Tris- $\mathrm{HCl}$ (pH 8.6); unbound protein was chromatographed on an agarose A1.5m column as described by Timpl et al. (22). The laminin appearing in the void volume was free of detectable entactin and was used as an immunogen to prepare rabbit antibodies to the whole molecule as well as for experiments in which laminin was coupled to glass coverslips to serve as a culture substratum. Antibody to this preparation was cross-absorbed against type IV collagen and eluted from an affinity column of whole laminin; by ELISA it was free of cross reactivity toward type IV collagen, fibronectin, and heparan sulfate proteoglycan. For detection of laminin by immunofluorescence or ELISA, it gave results essentially identical to those with the anti- $\mathbf{P}_{1}$ antibody.

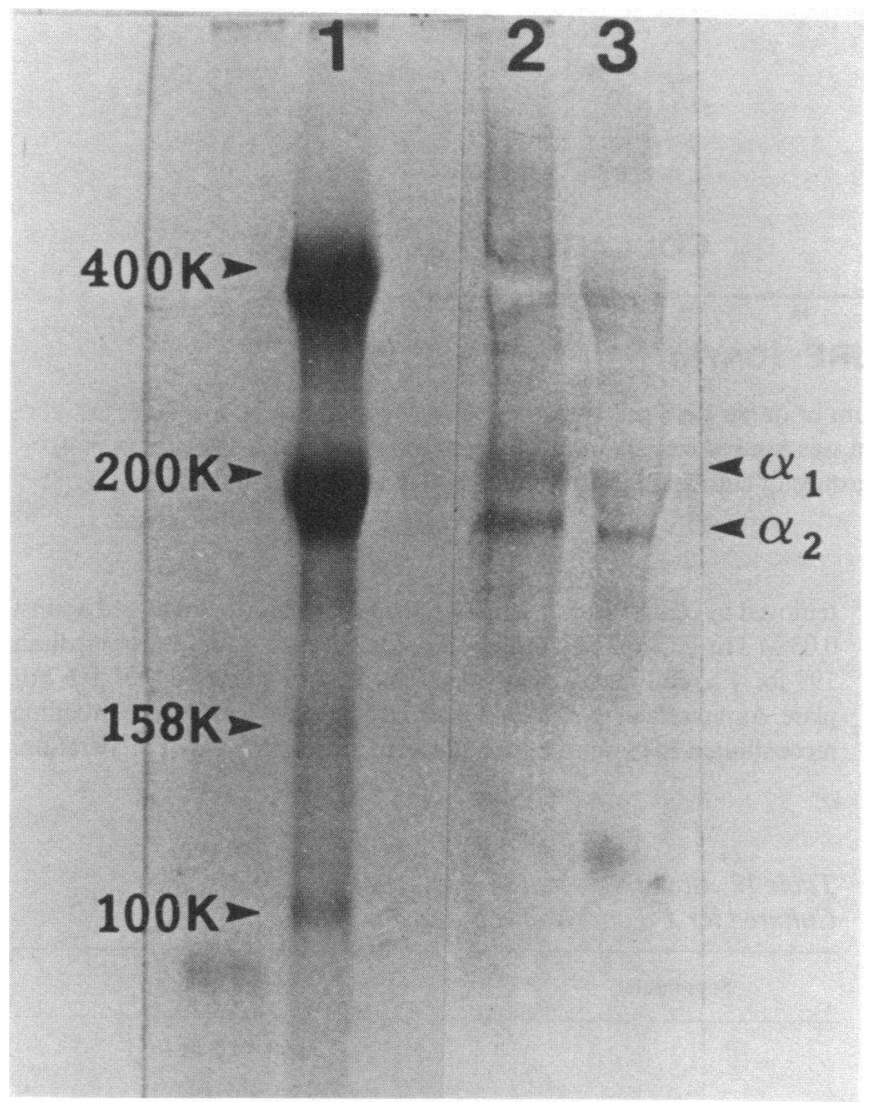

Figure 2. Analysis of reconstituted EHS gel by PAGE and immunoblotting. Lane 1, EHS gel (30 $\mu$ g protein) electrophoresed under reducing conditions on a 5\% polyacrylamide gel (Coomassie Blue stain). Lane 2, type IV collagen standard, electrophoresed under the same conditions, transferred to nitrocellulose paper and incubated with peroxidase-conjugated antibody to type IV collagen; a photograph of the paper after staining for peroxidase is shown. Lane 3, electrophoresis of EHS gel, identical to that in lane 1 , transferred to nitrocellulose and stained for type IV collagen, as in lane 2. The location of the alpha chains of type IV collagen is indicated on the right. Lane 3, two additional bands, at $\sim 400$ and $110 \mathrm{kD}$, which have not been characterized but may represent a dimer and a degradation product, respectively, of type IV collagen. The location of molecular mass standards is indicated on the left.
Type IV collagen was isolated by the method of Kleinman et al. (23) from the residue of the EHS tumor after laminin extraction. In brief, the material pelleted after guanidine extraction of laminin was treated twice with $2 \mathrm{M}$ guanidine buffer containing $2 \mathrm{mM}$ dithiothreitol (DTT). The pooled extracts containing collagen were dialyzed against $10 \% \mathrm{NaCl}$ in $50 \mathrm{mM}$ Tris- $\mathrm{HCl}$ (pH 7.4) containing $2 \mathrm{mM}$ DTT and protease inhibitors. Precipitated material was dialyzed into $4 \mathrm{M}$ urea, $0.25 \mathrm{M} \mathrm{NaCl}$, $0.002 \mathrm{M}$ DTT, and $0.05 \mathrm{M}$ Tris- $\mathrm{HCl}$ (pH 8.6) and passed over a DEAE column equilibrated and eluted with the same buffer. The unbound portion was analyzed by SDS PAGE on 5\% reducing gels and contained only the two chains of type IV collagen ( 210 and $185 \mathrm{kD})$. The collagen was stored on ice in $2 \mathrm{M}$ guanidine containing protease inhibitors. Rabbits were immunized with this material as previously described (25). The resulting antisera were cross-absorbed on columns of type I and III collagen and purified by affinity chromatography on a type IV collagen column. This antibody was found to have no cross reactivity with laminin by immunoblot, and its titer was 1:50,000 by ELISA.

Heparan sulfate proteoglycan (combined large and small forms) was isolated by a modification of the method of Hassell et al. (26). A portion of the EHS tumor was radiolabeled in vivo with $\mathrm{Na}_{2}{ }^{35} \mathrm{SO}_{4}$ to serve as a tracer. Fresh tumor was homogenized at $4^{\circ} \mathrm{C}$ and proteoglycans extracted for $24 \mathrm{~h}$ with $7 \mathrm{M}$ urea, $0.15 \mathrm{M} \mathrm{NaCl}$, and $0.05 \mathrm{M}$ Tris- $\mathrm{HCl}$ (pH 6.8) containing protease inhibitors. The supernate was dialyzed against $0.4 \%$ Triton X-100 in this buffer and batch-chromatographed on DEAE cellulose equilibrated with the same buffer. Proteoglycans were eluted by stepwise increases of $\mathrm{NaCl}$ from 0.2 to $1.0 \mathrm{M}$, and fractions with peak radioactivity were pooled. Precipitates obtained by addition of absolute methanol were solubilized with $4 \mathrm{M}$ guanidine containing $0.1 \%$ CHAPS (3-[(3-cholamidopropyl) dimethylammonium]-1-propane-sulfonate), and $0.02 \mathrm{M}$ Tris- $\mathrm{HCl}$ (pH 7.0), and chromatographed on a Sepharose CL4B column. Fractions corresponding to peaks of radioactivity were pooled, dialyzed against distilled water, and lyophilized. Proteoglycan was dissolved in $0.1 \mathrm{M}$ Tris- $\mathrm{HCl}$ ( $\mathrm{pH} \mathrm{8.5)} \mathrm{containing} 50 \mathrm{mM}$ DTT, $1 \%$ CHAPS, and $1 \mathrm{mM}$ EDTA, and incubated at $40^{\circ} \mathrm{C}$ for $2 \mathrm{~h}$. The incubate was adjusted to $7 \mathrm{M}$ urea by dialysis and batch-chromatographed on DEAE cellulose with a stepwise gradient of increasing $\mathrm{NaCl}$ concentrations as before. Fractions with peak radioactivity were assayed for uronic acid (27) to confirm proteoglycan content, combined, dialyzed against distilled water, and lyophilized. The purity and molecular size $(>400 \mathrm{kD})$ of the heparan sulfate proteoglycan was confirmed by SDS PAGE; the purified material was $12.5 \%$ uronic acid, by weight.

Affinity-purified antibody to human plasma fibronectin was the gift of Dr. Joseph Madri (Yale University, New Haven, CT) and was prepared as previously described (28). Rat plasma fibronectin was prepared by gelatin affinity chromatography (29).

Immunofluorescence microscopy. Immunofluorescence studies of normal rat liver were performed as described (30). In brief, cryostat sec-

\section{Table I. Composition of the Reconstituted EHS Matrix}

\begin{tabular}{ll}
\hline Constituent & Concentration \\
\hline & $\mathrm{mg} / \mathrm{ml} \mathrm{gel}$ \\
Laminin & $7.92 \pm 0.37$ \\
Type IV collagen & $0.57 \pm 0.05$ \\
Heparan sulfate proteoglycan & $0.40 \pm 0.03$ \\
Total protein & $8.75 \pm 0.67$ \\
\hline
\end{tabular}

Formed EHS gel was dissolved in guanidine and dialyzed before assay (see Methods). The data represent mean $\pm \operatorname{SD}(n=4)$. The amount of proteoglycan was calculated by assuming that it was $17 \%$ uronic acid, by weight (27). Protein was determined by the method of Lowry et al. (60). 


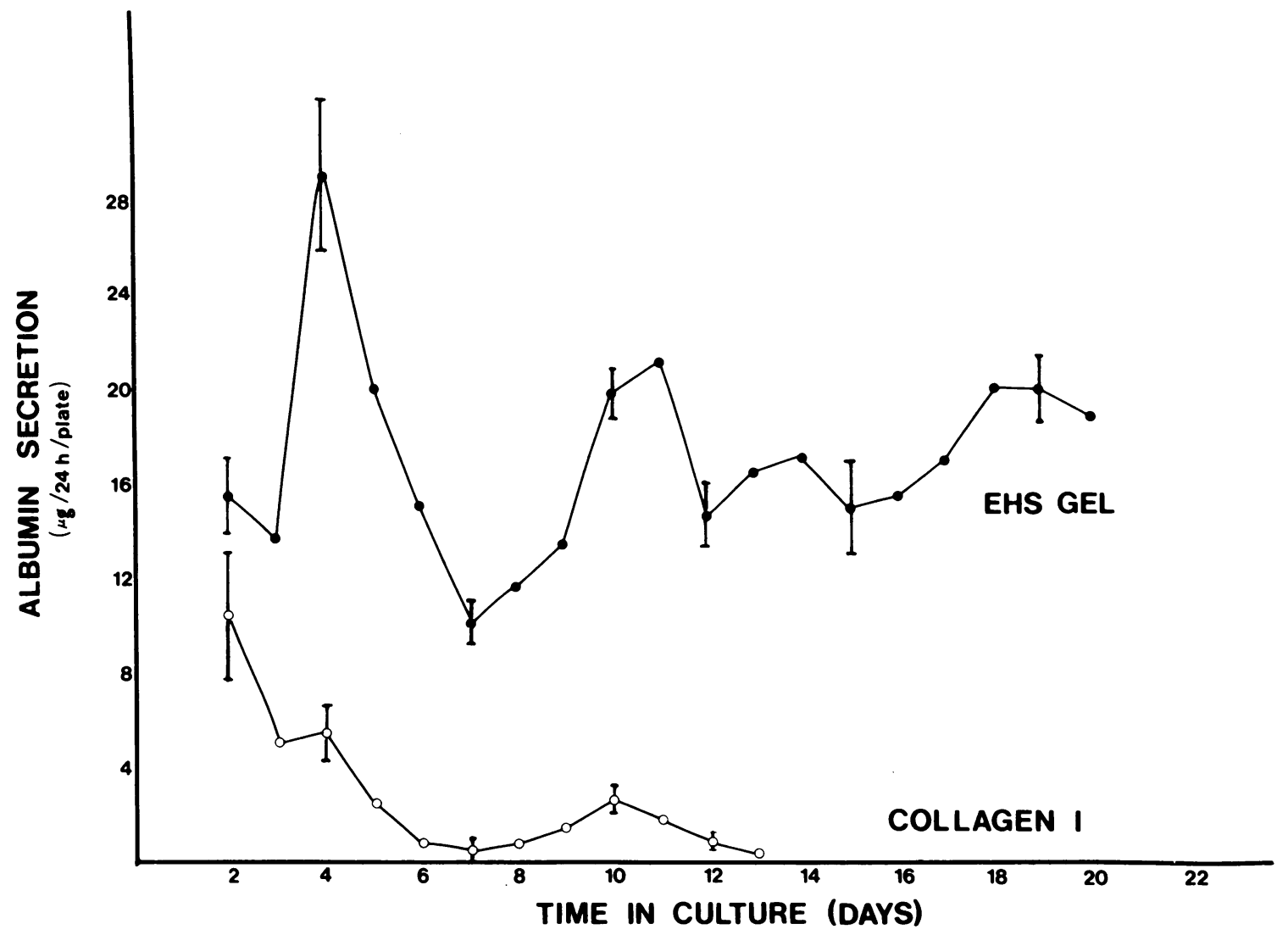

Figure 3. Albumin secretion by cells cultured on a type I collagen substratum or on an EHS gel. Hepatocytes were plated on the two different substrata. The medium contained 5\% FCS and was changed daily. Albumin was assayed serially in media from the same group of plates $(n=4$, for each substratum). The results show average secretion rates for the two groups of cultures; the error bars $( \pm S D)$ are representative.

tions $(6 \mu \mathrm{m})$ of rat liver were fixed with acetone for $10 \mathrm{~min}$, air-dried and incubated with either nonimmune rabbit IgG or affinity-purified primary antibodies for $1 \mathrm{~h}$. Sections were washed with phosphate-buffered saline (PBS) and incubated with a rhodamine-conjugated sheep antirabbit IgG (Dako Corp., Santa Barbara, CA) for $1 \mathrm{~h}$, followed by a second wash with PBS. Gelvatol mounting medium (Monsanto Co., St. Louis, MO) and a glass coverslip were applied. Sections were viewed with an Olympus BH microscope fitted with epi-illumination and rhodamine filters using Ektachrome ASA 400 film.

Cell culture. Dispersion of the liver with collagenase was carried out essentially as described previously (31). Hepatocyte suspensions were purified by centrifugal elutriation (32). The standard substratum consisted of acid-soluble collagen (type I) from rat-tail tendon (31); $\sim 20 \mu \mathrm{g}$ were applied to the surface of a $35-\mathrm{mm}$ plastic culture dish and allowed to dry at $21^{\circ} \mathrm{C}$. The same material was used to prepare gels of type I collagen (33). Other defined substrata were prepared by derivatization of $30-\mathrm{mm}$ round glass coverslips with purified matrix proteins (34).

The EHS sarcoma was raised in Swiss-Webster mice; the mice received drinking water containing $0.1 \%$ BAPN from the time the tumor became palpable ( $\sim 2 \mathrm{wk}$ after inoculation) until sacrifice. Harvested tissue was stored at $-70^{\circ} \mathrm{C}$. For preparation of a reconstituted basal lamina, the lathyritic tumor was homogenized in $3.4 \mathrm{M} \mathrm{NaCl}$ in $0.05 \mathrm{M}$ Tris- $\mathrm{HCl}$ (pH 7.4), $4 \mathrm{mM}$ EDTA, and $2 \mathrm{mM} N$-ethylmaleimide using a Polytron (Brinkmann Instruments Co., Westbury, NY). After centrifugation ( $50,000 \mathrm{~g}$ for $20 \mathrm{~min}$ ), pelleted material was suspended by manual homogenization in the same salt solution and then repelleted as above; this procedure was repeated for a total of two washes. The final pellet was extracted with $2 \mathrm{M}$ urea as described (35) except that the extraction was carried out with $1.8 \mathrm{ml}$ solvent/g tissue weight. Insoluble material was removed by centrifugation, as above; the supernatant was dialyzed against $0.05 \mathrm{M}$ Tris- $\mathrm{HCl} / 0.2 \mathrm{M} \mathrm{NaCl}$ ( $\mathrm{pH} 7.0$ ) for $2 \mathrm{~d}$, against serum-free medium 199 for $4 \mathrm{~h}$, and then was pipetted into $35-\mathrm{mm}$ culture dishes, $0.6 \mathrm{ml} /$ plate. As it warmed to $37^{\circ} \mathrm{C}$, it formed a firm, clear gel. Plates containing reconstituted EHS matrix generally were used within $2 \mathrm{~d}$ of preparation.

Table II. Albumin Secretion by Hepatocytes Cultured for $4 d$ on Various Substrata

\begin{tabular}{ll}
\hline Substratum & Albumin secretion \\
\hline & $\mu g / 24 h$ per $\mu g$ DNA \\
Type I collagen & $0.35 \pm 0.09$ \\
Type IV collagen & $0.29 \pm 0.12$ \\
Laminin & $0.58 \pm 0.02$ \\
Fibronectin & $0.66 \pm 0.06$ \\
EHS gel & $5.00 \pm 0.16$ \\
\hline
\end{tabular}

Substrata were prepared by derivatization of glass coverslips, as described in Methods; the density of the protein coating was estimated at $150 \mathrm{ng} / \mathrm{cm}^{2}$, which provides for maximal cell attachment (40). Hepatocytes were plated in serum-free medium, which was changed daily. Albumin secretion on the fourth day of culture was measured by ELISA. The results are expressed as mean $\pm \mathrm{SD}(n=3-6)$. Albumin synthesis in vivo is in the range $1.2-1.6 \mu \mathrm{g} / 24 \mathrm{~h}$ per $\mu \mathrm{g}$ DNA (38). 
All procedures up to gel formation were carried out at $4^{\circ} \mathrm{C}$. Sterility was maintained by the use of boiled dialysis tubing and filtered $(0.22 \mu \mathrm{m})$ solutions.

$\sim 1.5 \times 10^{6}$ hepatocytes were plated in a modified medium 199 (32). Serum-free medium contained $0.1 \%$ (wt/vol) bovine serum albumin. Serum, when present, was in the form of fetal calf serum (FCS; Flow Laboratories, Inc., McLean, VA) at a concentration of $5 \%$ (vol/vol). Media were changed $4 \mathrm{~h}$ after plating and at 24-h intervals thereafter.

Assays. EHS gel was dissolved at $4^{\circ} \mathrm{C}$ in $2 \mathrm{M}$ guanidine containing $4 \mathrm{mM}$ EDTA and $0.05 \mathrm{M}$ Tris (pH 7.4), then dialyzed against PBS. Aliquots of this solution were taken for protein determination and immunoassay of individual matrix proteins. Type IV collagen and laminin were measured by inhibition ELISA (19) and expressed as milligrams per milliliter of original gel. Aliquots were analyzed also by electrophoresis on $5 \%$ SDS polyacrylamide gels after reduction with $1 \%$ mercaptoethanol. Transfer of proteins to nitrocellulose paper and immunoblotting were carried out as described (36). A peroxidase-conjugated secondary antibody was used (goat anti-rabbit IgG; Cappell Laboratories/Cooper Biomedical, Malvern, PA). Heparan sulfate proteoglycan was measured as uronic acid (27).

Albumin was measured by ELISA (19). Pure rat albumin and antirat albumin were purchased from Cappel Laboratories. Results were quantitated with a Titertek microELISA reader (Flow Laboratories, Inc.). With respect to cultures containing FCS, cross reactivity of bovine albumin with the antibody to rat albumin was negligible. Results are expressed per microgram DNA, which was measured fluorometrically (37); they have been corrected for the amount of DNA in the EHS gel (9-10 $\mu \mathrm{g} /$ plate), which was determined from sister plates containing gel alone. With a medium change of plates containing EHS gel, $\sim 85 \%$ of the albumin in the culture was recovered, $15 \%$ remaining in the gel and carrying over to the subsequent measurement period. The results shown have not been adjusted for this carryover.

For measurement of total cellular cytochrome $P-450$, cell layers were washed with cold $0.1 \mathrm{M}$ potassium phosphate ( $\mathrm{pH} 7.4$ ), scraped into the same buffer, and disrupted by brief sonication. The hemeprotein was measured by difference spectrophotometry of the whole lysate (31).

Electron microscopy. Cultures were fixed for $2 \mathrm{~h}$ in a mixture of $0.8 \%$ paraformaldehyde and $2.5 \%$ glutaraldehyde in $0.2 \mathrm{M}$ cacodylate buffer (pH 7.4), washed in veronal acetate buffer containing 7\% sucrose (pH 7.4) and osmicated ( $1 \% \mathrm{OsO}_{4}$ in veronal acetate buffer). After staining with $1 \%$ uranyl acetate for $1 \mathrm{~h}$, the specimens were dehydrated through graded ethanols and embedded in LX-112 (Ladd Research Industries, Inc., Burlington, VT). Sections were viewed with a Phillips 201 microscope.

\section{Results}

The subendothelial space of normal rat liver contains the principal proteins of a basal lamina. Frozen sections of rat liver were

Table III. Total Cytochrome P-450 in Cells Cultured on EHS Gel or Type I Collagen

\begin{tabular}{|c|c|c|}
\hline \multirow[b]{2}{*}{ Substratum } & \multicolumn{2}{|c|}{ Cytochrome P-450 } \\
\hline & Culture day 3 & Culture day 6 \\
\hline & 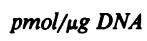 & 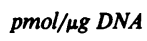 \\
\hline EHS gel & $3.1 \pm 0.7$ & $1.2 \pm 0.2$ \\
\hline Type I collagen & $1.1 \pm 0.5$ & $0.3 \pm 0.2$ \\
\hline
\end{tabular}

Hepatocytes were plated in medium containing $5 \%$ fetal calf serum. On days 3 and 6 after plating, cells were processed for measurement of cytochrome P-450. The data represent mean $\pm \mathrm{SD}(n=4-8)$. Cytochrome $\mathrm{P}-450$ in freshly isolated cells averages $5.2 \mathrm{pmol} / \mu \mathrm{g}$ DNA (31). incubated with affinity-purified antibodies to the major basal lamina proteins and examined by immunofluorescence microscopy. Type IV collagen, fibronectin, and laminin were found around major vessels and, within the parenchyma, in a distribution that coincides with the subendothelial (Disse) space. In contrast, type I collagen was present in portal areas and as thick bundles that course randomly through the hepatic lobule (Fig. 1).

A laminin-rich gel matrix supports differentiated liver functions in culture. The compositions of the gelled, reconstituted EHS matrix was examined electrophoretically and was found to consist of laminin predominantly (Fig. 2, lane 1); two smaller bands with 158 and $100 \mathrm{kD}$, respectively, were visible, migrating in the position of entactin/nidogen, which is a minor glycoprotein component of basal laminae (35). Gels overloaded with protein
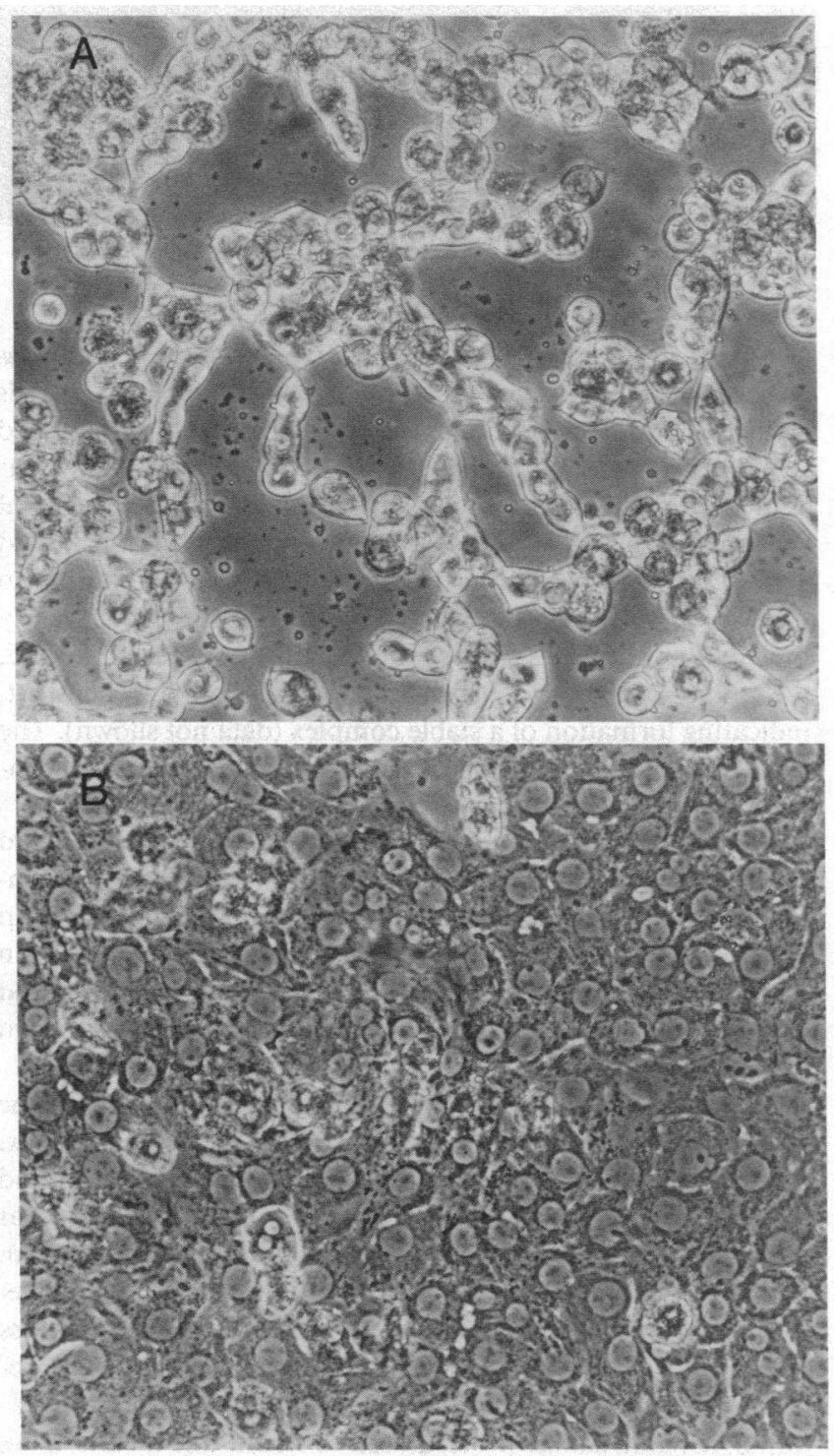

Figure 4. Phase-contrast microscopy of hepatocytes cultured for $48 \mathrm{~h}$ on EHS gel or type I collagen. The photomicrographs depict hepatocytes cultured on EHS gel $(A)$, and cells from the same initial preparation plated on a conventional substratum of type I collagen $(B)$. (X 170). 


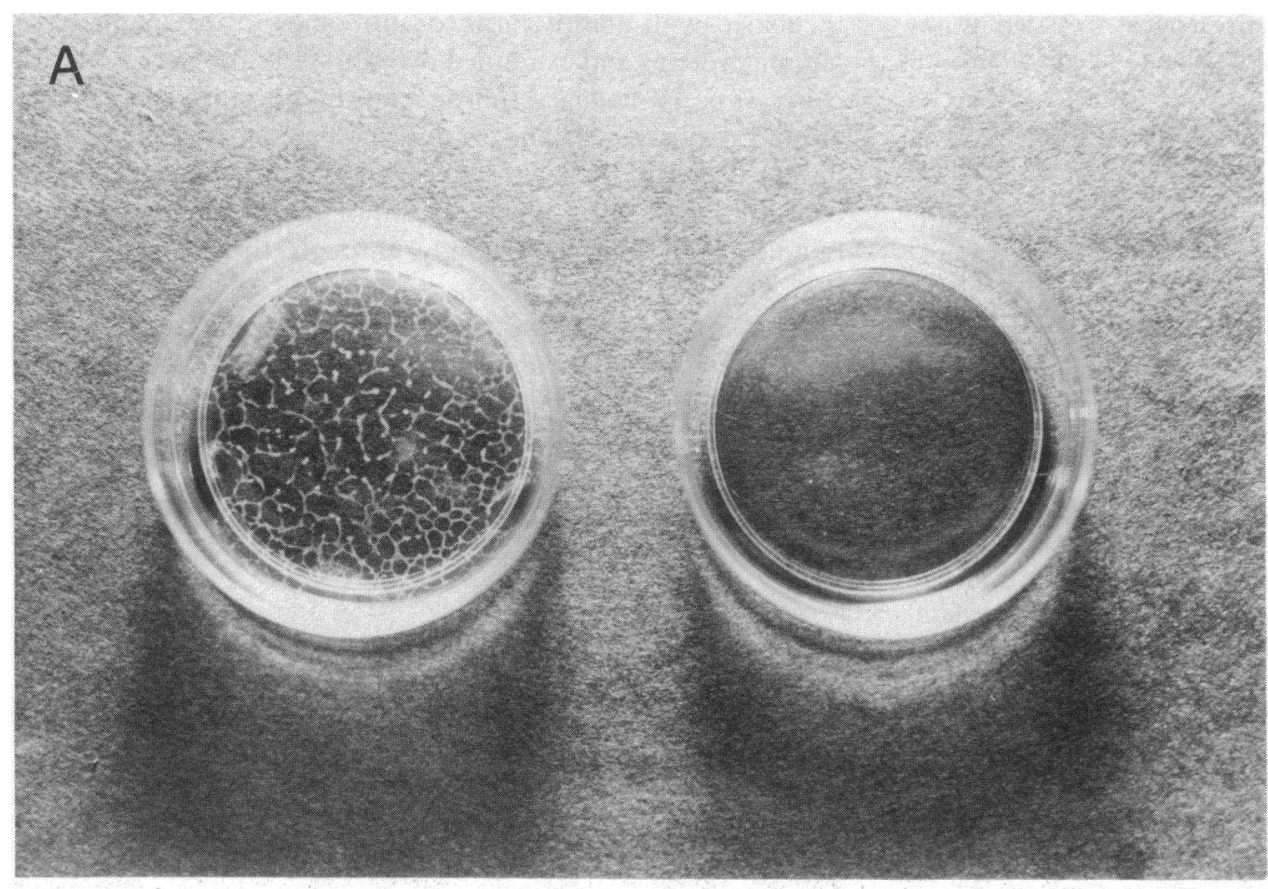

Figure 5. The gross and microscopic appearance of hepatocytes after $10 \mathrm{~d}$ of culture. The reorganization of hepatocytes cultured on an EHS gel into thick columns is apparent from inspection of the plates $(A$, left); this may be compared with a conventional culture of the same age ( $A$, right), which appears empty but microscopically contained a continuous layer of flattened cells. Under phase-contrast microscopy, the thick columns consisted of hepatocytes at multiple levels; a single field at two different levels of focus is shown ( $B$ and $C, \times 170$ ). and silver-stained demonstrated additional lower molecular mass bands (not shown). Type IV collagen was not apparent on gels stained for protein (Coomassie Blue), because it co-migrated with the smaller subunit ( $200 \mathrm{kD}$ or B chain) of laminin; it was demonstrated by immunoblot of the electrophoresed material (Fig. 2, lane 3). In a typical preparation, laminin constituted $91 \%$ of the total protein in the gel, and the ratio of laminin to type IV collagen was 14:1 (Table I). In initial extracts, freshly prepared gels and gels subjected to changes of medium for $3 \mathrm{~d}$, the ratio of laminin to collagen IV remained essentially constant, indicating formation of a stable complex (data not shown). The amount of heparan sulfate, estimated from the uronic acid content of the gel, was similar to that reported elsewhere (35).

Hepatocytes were plated on this material or on a standard substratum of type I collagen, and albumin secretion was monitored daily. In cultures on the standard substratum, albumin secretion declined after $2 \mathrm{~d}$, as reported previously $(38,39)$. In marked contrast, secretion by cells on the EHS gel was sustained at a rate that is similar to that calculated for hepatocytes in vivo (Fig. 3) (38).

We next examined whether individual components of the EHS gel were capable of substituting for the intact gel complex. Substrata consisting of purified laminin, type IV collagen, and heparan sulfate proteoglycan, respectively, were prepared as outlined in Methods. The effect of fibronectin also was studied. During the initial days of culture, deterioration of albumin secretion occurred on all substrata, although the decline was less pronounced for cultures on the glycoproteins (laminin, fibronectin) than for those on the collagens (Table II). On a substratum of heparan sulfate proteoglycan in serum-free medium, hepatocytes formed spherical multi-cell aggregates that were free floating or formed only a tenuous attachment to the surface of the dish. As a test of whether the physical properties per se of a gel were responsible for the positive effect of the EHS matrix, a gel of type I collagen was prepared (type IV collagen fails to form a stable gel at physiological pH). Hepatocytes functioned no better on this material than on a thin layer of type I collagen (data not shown).

The effects of a complex substratum on hepatocyte function are broad. Cytochrome P-450 in cells cultured on EHS gel was approximately threefold that of cells on the conventional collagen substratum, although relative to normal liver, decreases occurred in both types of culture (Table III). Secretion of hemopexin by cells on EHS gel also was enhanced, paralleling the data for albumin secretion (D. M. Bissell and U. Muller-Eberhard, unpublished observations). The differences in protein secretion were found to be expressed at the level of mRNA; in addition, mRNA for alpha-1-acid glycoprotein was stable in hepatocytes on the EHS gel while dropping to $10 \%$ of normal in conventional cultures (M. McPhaul and D. M. Bissell, unpublished observations). These findings suggest that the effects of extracellular matrix on the expression of liver-specific functions occur at the level of gene transcription and/or mRNA turnover.

Morphologic correlates. The effects of substratum on the morphology of hepatocytes in culture similarly were striking. When cultured on EHS gel, cells attached rapidly but exhibited minimal spreading, forming columns instead (Fig. $4 A$ ). This was in marked contrast to cells cultured on collagen (Fig. $4 \mathrm{~B}$ ), which had the flattened appearance that is typical of epithelial cells maintained long-term on plastic. On laminin, spreading proceeded more slowly (40) but within $48 \mathrm{~h}$ after plating was similar to that exhibited by cells on collagen. The extent of spreading was a function, in part, of the density of cells in the plate but, at all densities, the cells exhibited a tendency to form a continuous monolayer of cells (Fig. $4 \mathrm{~B}$ ).

These morphologic differences persisted as cultures aged. Cells on the EHS gel remained grouped in columns, which condensed and thickened until, after 1 wk of culture, they were grossly apparent (Fig. $5 \mathrm{~A}$ ). At this time, the organization of the columns was complex, with grouped hepatocytes at more than one microscopic level (Fig. $5 B$ and $C$ ). Preservation of function in such cultures was excellent (Fig. 3). In cultures on defined 

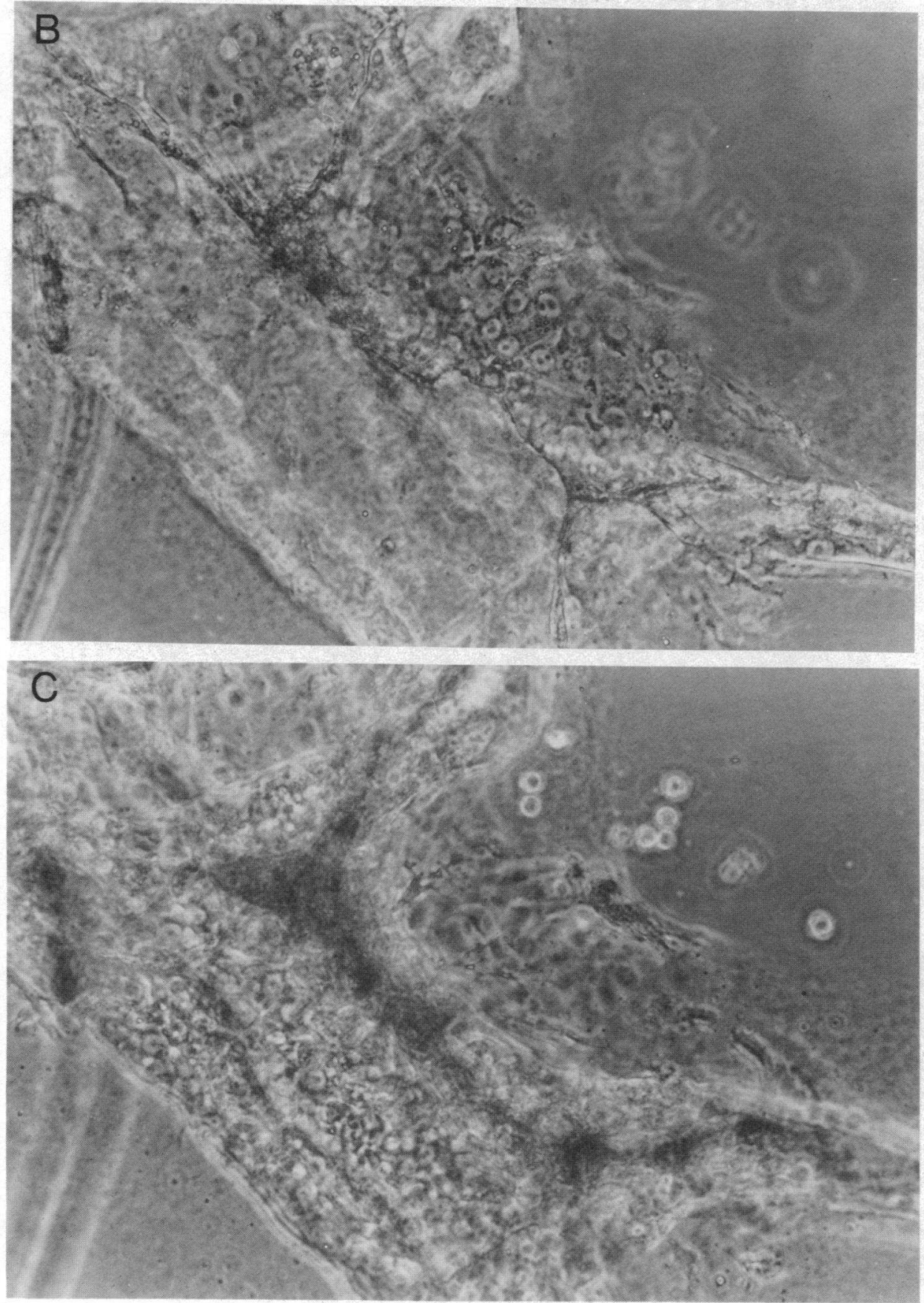

Figure 5. (Continued)

substrata other than heparan sulfate proteoglycan, spreading was progressive with thinning of the cells and loss of the granularity that is characteristic of newly cultured hepatocytes. Also, mesenchymal cells became prominent in conventional cultures maintained longer than $1 \mathrm{wk}$ and rapidly took over cultures in serum-containing medium. On the EHS gel, mesenchymal cells could be seen at the periphery of grouped hepatocytes, but outgrowth was minimal during a 3-wk period of observation, regardless of the presence of serum in the medium.

The ultrastructural features of hepatocytes on EHS and on type I collagen gels were compared (Fig. 6). Hepatocytes cultured on EHS gel remained cuboidal, with abundant smooth and rough endoplasmic reticulum and numerous Golgi complexes. In parallel cultures on collagen, the cells were attenuated with a height- width ratio of $\sim 1: 20$ and lacked many characteristics of normal liver; particularly noteworthy was a paucity of endoplasmic reticulum and Golgi complexes. At the interface between the cell and the gel substratum, hepatocytes on collagen were flat, without membrane specialization, whereas those on EHS matrix exhibited many areas with microvilli (Fig. 7).

\section{Discussion}

The response of hepatocytes in culture to a complex substratum differs strikingly from that of cells on individual matrix proteins or on uncoated tissue-culture plastic. It appears that only a complex of basal lamina proteins strongly supports hepatocellular function, and from this we infer that the matrix proteins in the 

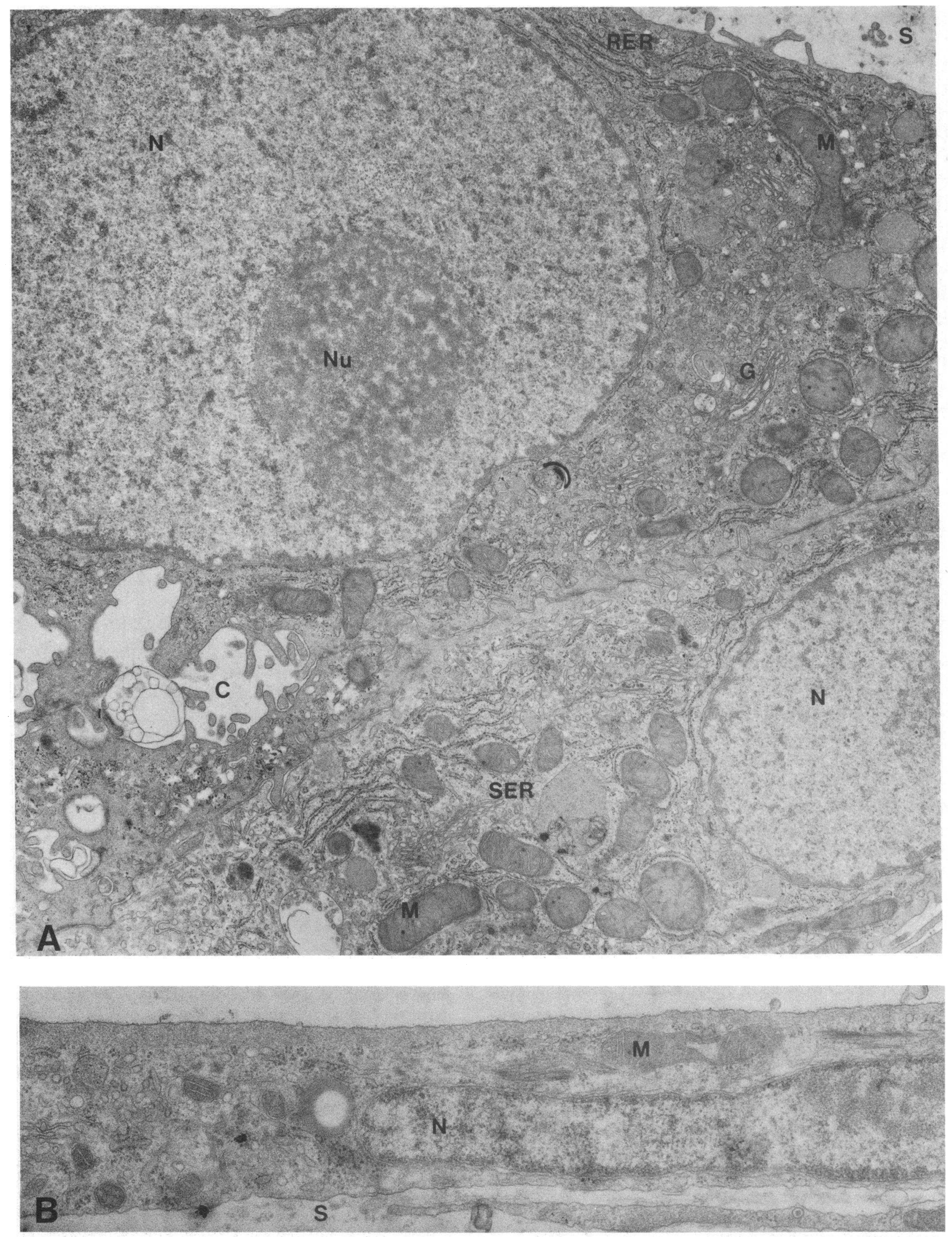


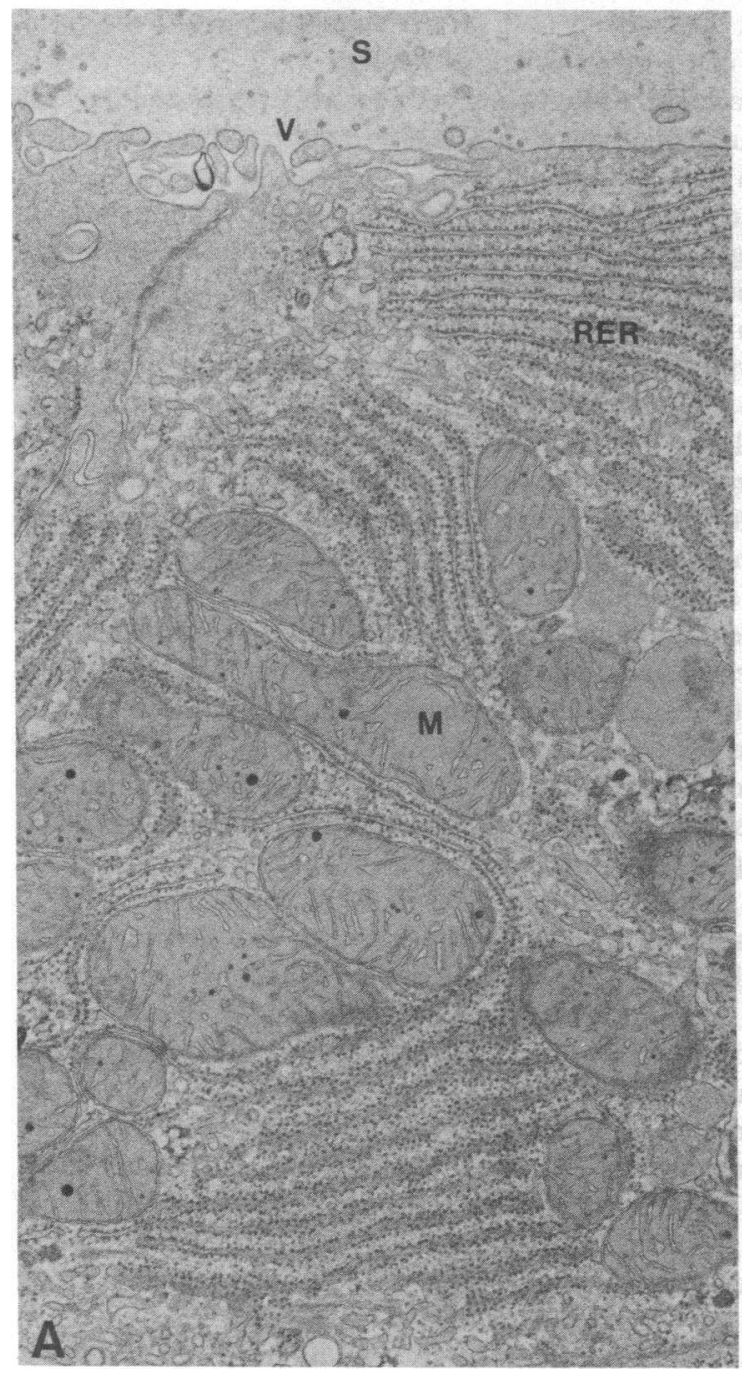

Figure 7. Organelle structure of hepatocytes cultured on an EHS gel. Microvilli $(V)$ are present at the interface with the substratum, and there is abundant rough endoplasmic reticulum $(A)$. A canaliculus-like structure with junctional complexes $(J)$ is formed by the plasma mem-

subendothelial space, visualized by immunofluorescence, constitute a functionally significant basal lamina.

The EHS tumor was grown in animals treated with betaaminopropionic acid. By extracting lathyritic tumor, we recovered more type IV collagen and proteoglycan in the initial urea solution than did Kleinman and colleagues (35) and have found it unnecessary to supplement the extract with these substances to obtain a stable gel that is suitable as a culture substratum. The content of heparan sulfate proteoglycan in our native extract is similar to that in the supplemented extract, and the formed gel has the ultrastructural appearance of irregularly branching thin sheets (not shown) described previously (35). branes of three individual cells $(B)$. The cells contain numerous, well developed Golgi complexes $(C)$. Other labels are as in Fig. 6. $(A$, $\times 25,000 ; B$ and $C, \times 21,000)$.

This preparation presents a surface highly enriched in laminin to the cells in culture. Whether the immediate extracellular environment of an intact epithelium also consists of laminin is conjectural but is supported by current models based on morphologic information (41). Collagen appears to comprise the core of the basement membrane, extending through all its layers, but is coated with glycoprotein and proteoglycan (42). By this arrangement, cells may be in contact normally with collagenassociated glycoproteins such as laminin rather than with collagen itself. In the liver, the presence of laminin in the subendothelial space is controversial $(11,12)$, although other basementmembrane components (type IV collagen, heparan sulfate
Figure 6. The ultrastructural morphology of hepatocytes cultured on defined or complex substrata. Hepatocytes were cultured for $2 \mathrm{wk}$ on an EHS gel $(A)$ or on a gel of type I collagen $(B)$. Preparations were sectioned perpendicularly to the plane of the culture. Notable differences between the two types of culture include the presence of micro- villi at the cell-substratum interface $(S)$, and the relatively well preserved smooth (SER) and rough (RER) endoplasmic reticulum and Golgi complexes $(G)$ in the cells cultured on the EHS gel. Also noted are canaliculus-like structures $(C)$, nuclei $(N)$, and mitochondria $(M)$. $(A, \times 13,500 ; B, \times 25,000)$. 
proteoglycan) are found $(7,8)$. The basis for the divergent findings regarding hepatic laminin is unknown but may reflect the use of anti-laminin of varying titer. Also, the intensity of staining of laminin is less in the sinusoids than around lobular vessels (Fig. $1 \mathrm{~A}$ ) and requires a sensitive fluorescence detection system for adequate visualization. Our findings suggest that hepatocytes, like other epithelial cells, are in contact with laminin at their basal surface.

The morphology of hepatocytes cultured on EHS gel is characteristic. Rather than attaching individually and spreading rapidly, as on collagen, the cells form irregular cords. The appearance suggests that cell-cell interaction is enhanced under these conditions. Prior studies with hepatocytes in culture provide evidence that aggregation per se preserves the expression of differentiated functions (43). Is it then possible that the EHS gel functions only passively, fostering aggregation by presenting a neutral surface to the cells? Several kinds of observations argue against this interpretation. The time course of cell attachment to the EHS gel is similar to that for attachment to collagen (40), in contrast to the slow and very limited attachment of hepatocytes to an inert surface such as glass. The attachment itself is firm, being resistant to both mechanical agitation and calcium chelation (unpublished observations). The period of functional stability (and viability) of adult rat hepatocyte aggregates in suspension does not exceed $48 \mathrm{~h}$ (43), whereas hepatocytes maintained on EHS gels are stable for at least $3 \mathrm{wk}$ (Fig. 3). A recent report by Landry and co-workers (44) showed that hepatocytes from newborn rat liver will survive and function for weeks as free-floating spheroids. However, the aggregates incorporated a significant mesenchymal element, undergoing histiotypic organization including matrix deposition during cultivation in vitro. The factors responsible for hepatocyte survival in this system have not been analyzed individually, but matrix formation appears to play a major role (44). In this respect, the study supports the view expressed here, that cell-matrix interaction-in addition to cell-cell association-is central to the expression of specific functions by hepatocytes.

Suggestive evidence for a metabolic effect of extracellular matrix in hepatocyte cultures is presented in several previous studies. Michalopoulos and co-workers showed that the loss of cytochrome P-450 occurring over the first $24 \mathrm{~h}$ in cells cultured on plastic, was partially prevented when cells were plated on a collagen gel (45). Rojkind and colleagues extracted rat liver collagen and associated glycoproteins, calling it biomatrix, and examined its use as a culture substratum (46). The material was inhomogeneous, with glycoprotein-rich and glycoprotein-poor areas (apparently collagen). A noteworthy finding was that only the glycoprotein-rich areas were capable of supporting long-term survival of hepatocytes. While the detailed composition of this substratum is unknown, the data suggest that a complex of collagen and collagen-associated glycoproteins is required for optimal support of hepatocyte function in culture, in agreement with the present findings. Most recently, Guguen-Guillouzo and colleagues have described a system in which normal hepatocytes (rat or human) are maintained in co-culture with an epithelial cell line, also derived from rat liver (47). Hepatocytes exist in groups surrounded by the cell line, and exhibit a number of differentiated functions. A salient feature of the co-cultures is the abundant matrix elaborated at the interface between the two cell types, absent in pure cultures of either cell (47). Characterization of this matrix is as yet incomplete. Type III collagen is present, qualitatively (48); further studies to identify the glycoprotein components will be of interest.

Details of the interaction between hepatocytes and the EHS gel are under investigation. While current models postulate that laminin is the attachment protein for epithelial cells (49), it has been shown that hepatocytes bind not only to laminin but also to collagen and fibronectin, apparently by distinct receptor-mediated interactions $(40,50-52)$. Spreading of hepatocytes on laminin is substantially slower than spreading on collagens (type IV or type I) (40), resembling that on the EHS gel. On the other hand, a substratum of pure laminin, while better than pure collagen, clearly is inferior to the EHS gel for support of hepatocyte function (Table II). In short, molecular characterization of the interaction of hepatocytes with the reconstituted gel remains to be defined. It cannot be excluded that hepatocytes attach, in fact, to minor proteins of the gel including entactin (53). However, the importance of these minor glycoproteins to either the structural or functional properties of basal laminae is unknown. Alternatively, laminin may require a specific conformation to function optimally as an attachment protein, a conformation acquired only when complexed with other basal lamina constituents. Evidence for specific interactions among these proteins is emerging from a number of recent studies. Self-aggregation of both laminin (54) and type IV collagen (55) occurs; these proteins interact (41), and each interacts with heparan sulfate proteoglycan $(41,56,57)$. The impact of these associations on tertiary protein structure and the conformation of cell-binding sites is conjectural but could be significant for a protein as large as laminin $\left(10^{6} \mathrm{D}\right)$.

Extrapolation of these data to the intact liver suggests a new basis for altered liver function in hepatic fibrosis. Subendothelial fibrosis is a serious form of liver injury (58); when the extent of fibrosis is quantitated by electron microscopy, it correlates with the severity of clinical liver disease (59). Hepatocytes exhibit marked loss of microvilli, resembling in this respect cells cultured on a collagen substratum. It has been proposed that subendothelial collagen acts as a barrier to the normal exchange of nutrients and metabolites across the Disse space and thereby causes hepatocellular dysfunction (58). The present findings suggest that, if collagen is a key protein in this lesion, it is not merely because it creates a barrier but because it alters the structure of the basal lamina, disrupting the cell-matrix relationships that support normal hepatocellular function. With controlled manipulation of the culture system, it will be possible to define in detail these interactions and to characterize their physiologic or pathologic nature.

\section{Acknowledgments}

Okhi Choun, Alan Sato, Mary Barker, and Heather Mates provided expert assistance with various aspects of the work. Antibody to human plasma fibronectin was the generous gift of Dr. Joseph Madri (Yale University).

This work was supported in part by U. S. Public Health Service grants, from the National Institutes of Health (AM-31198, IP30 AM26743, and T32 AM-07007), and from the National Institute on Alcohol Abuse and Alcoholism (AA 06092).

\section{References}

1. Timpl, R., and G. R. Martin. 1982. Components of basement membranes. In Immunochemistry of the Extracellular Matrix. $\mathrm{H}$. Furthmayr, editor. CRC Press, Inc., Boca Raton, FL. 119-150. 
2. Aplin, J. D., and R. C. Hughes. 1982. Complex carbohydrates of the extracellular matrix. Structures, interactions and biological roles. Biochim. Biophys. Acta. 694:375-418.

3. Wessells, N. K. 1977. Tissue Interaction and Development. W. A. Benjamin, New York.

4. Hay, E. D. 1984. Cell-matrix interaction in the embryo: cell shape, cell surface, cell skeletons and their role in differentiation. In The Role of Extracellular Matrix in Development. R. L. Trelstad, editor. Alan R. Liss, Inc., New York. 1-31.

5. Hadley, M. A., S. W. Byers, C. A. Suarez-Quian, H. K. Kleinman, and M. Dym. 1985. Extracellular matrix regulates Sertoli cell differentiation, testicular cord formation, and germ cell development in vitro. J. Cell Biol. 101:1511-1522.

6. Lee, E. Y.-H., G. Parry, and M. J. Bissell. 1984. Modulation of secreted proteins of mouse mammary epithelial cells by the collagenous substrata. J. Cell Biol. 98:146-155.

7. Rojkind, M., and P. Ponce-Noyola. 1982. The extracellular matrix of the liver. Collagen Related Res. 2:151-175.

8. Stow, J. L., L. Kjellen, E. Unger, M. Hook, and M. G. Farquhar. 1985. Heparan sulfate proteoglycans are concentrated on the sinusoidal plasmalemmal domain and in intracellular organelles of hepatocytes. $J$. Cell Biol. 100:975-980.

9. Oh, E., M. Peirschbacher, and E. Ruoslahti. 1981. Deposition of plasma fibronectin in tissues. Proc. Natl. Acad. Sci. USA. 78:3218-3221.

10. Hogan, B. L. M., A. R. Cooper, and M. Kurkinen. 1980. Incorporation into Reichert's membrane of laminin-like extracellular proteins synthesized by parietal endoderm cells of the mouse embryo. Dev. Biol. 80:289-300.

11. Martinez-Hernandez, A. 1984. The hepatic extracellular matrix. I. Electron immunohistochemical studies in normal rat liver. Lab. Invest. 51:57-74.

12. Abramson, D. R., and J. D. Caulfield. 1985. Distribution of laminin within rat and mouse renal, splenic, intestinal, and hepatic basement membranes identified after the intravenous injection of heterologous antilaminin IgG. Lab. Invest. 52:169-181.

13. Maher, J. J., S. L. Friedman, F. J. Roll, and D. M. Bissell. 1985. Laminin production by lipocytes cultured from normal rat liver. $\mathrm{He}$ patology. 5:1038.

14. Friedman, S. L., F. J. Roll, J. Boyles, and D. M. Bissell. 1985. Hepatic lipocytes: the principal collagen-producing cells of normal rat liver. Proc. Natl. Acad. Sci. USA. 82:8681-8685.

15. Wanson, J. C., P. Drochmans, R. Mosselmans, and M. F. Ronveaux. 1977. Adult rat hepatocytes in primary monolayer culture. Ultrastructural characteristics of intercellular contacts and cell membrane differentiations. J. Cell Biol. 74:858-877.

16. Barth, C. A., and L. R. Schwarz. 1982. Transcellular transport of fluorescein in hepatocyte monolayers: evidence for functional polarity of cells in culture. Proc. Natl. Acad. Sci. USA. 79:4985-4987.

17. Trelstad, R. L., V. M. Catanese, and D. F. Rubin. 1976. Collagen fractionation: separation of native types I, II and III by differential precipitation. Anal. Biochem. 71:114-118.

18. Roll, F. J., J. A. Madri, and H. Furthmayr. 1979. A new method of iodinating collagen for use in radioimmunoassay. Anal. Biochem. 96: 489-499.

19. Madri, J. A., and K. W. Barwick. 1983. Use of avidin-biotin complex in an ELISA system: a quantitative comparison with two other immunoperoxidase detection systems using keratin antisera. Lab. Invest. 48:98-107.

20. Madri, J. A., S. K. Williams, T. Wyatt, and C. Mezzio. 1983. Capillary endothelial cell cultures: phenotypic modulation by matrix components. J. Cell Biol. 97:153-165.

21. Orkin, R. W., P. Gehron, E. B. McGoodwin, G. R. Martin, T. Valentine, and R. Swarm. 1977. A murine tumor producing a matrix of basement membrane. J. Exp. Med. 145:204-220.

22. Timpl, R., H. Rohde, P. G. Robey, S. I. Rennard, J. M. Foidart, and G. R. Martin. 1979. Laminin-a glycoprotein from basement membranes. J. Biol. Chem. 254:9933-9937.
23. Kleinman, H. K., M. L. McGarvey, L. A. Liotta, P. G. Robey, K. Tryggvason, and G. R. Martin. 1982. Isolation and characterization of type IV procollagen, laminin, and heparan sulfate proteoglycan from the EHS sarcoma. Biochemistry. 21:6188-6193.

24. Rohde, H., G. Wick, and R. Timpl. 1979. Immunochemical characterization of the basement membrane glycoprotein laminin. Eur. J. Biochem. 102:195-201.

25. Roll, F. J., J. A. Madri, J. Albert, and H. Furthmayr. 1980. Codistribution of collagen types IV and AB2 in basement membranes and mesangium of the kidney. J. Cell Biol. 85:597-616.

26. Hassell, J. R., W. C. Leyshon, S. R. Ledbetter, B. Tyree, S. Suzuki, M. Kato, K. Kimata, and H. K. Kleinman. 1985. Isolation of two forms of basement membrane proteoglycans. J. Biol. Chem. 260:8098-8105.

27. Blumenkrantz, N., and G. Asboe-Hansen. 1973. New method for quantitative determination of uronic acids. Anal. Biochem. 54:484489.

28. Madri, J. A., F. J. Roll, H. Furthmayr, and J.-M. Foidart. 1980. Ultrastructural localization of fibronectin and laminin in the basement membranes of the murine kidney. J. Cell Biol. 86:682-687.

29. Engvall, E., and E. Ruoslahti. 1977. Binding of soluble form of fibroblast surface protein, fibronectin, to collagen. Int. J. Cancer. 20:1-5.

30. Roll, F. J., and J. A. Madri. 1982. Immunocytochemical techniques in connective tissue research. In Immunochemistry of the Extracellular Matrix. H. Furthmayr, editor. CRC Press, Inc., Boca Raton, FL. 49-88.

31. Bissell, D. M., and P. S. Guzelian. 1980. Phenotypic stability of adult rat hepatocytes in primary monolayer culture. Ann. $N Y$ Acad. Sci. 349:85-98.

32. Irving, M. G., F. J. Roll, S. Huang, and D. M. Bissell. 1984. Characterization and culture of sinusoidal endothelium from normal rat liver: lipoprotein uptake and collagen phenotype. Gastroenterology. 87: 1233-1247.

33. Elsdale, T., and J. Bard. 1972. Collagen substrata for studies on cell behavior. J. Cell Biol. 54:626-637.

34. Aplin, J. D., and R. C. Hughes. 1981. Protein-derivatised glass coverslips for the study of cell-to-substratum adhesion. Anal. Biochem. 113:144-148.

35. Kleinman, H. K., M. L. McGarvey, J. R. Hassell, V. Star, F. B. Cannon, G. W. Laurie, and G. R. Martin. 1985. Basement membrane complexes with biological activity. Biochemistry. 25:312-318.

36. Towbin, H., T. Staehelin, and J. Gordon. 1979. Electrophoretic transfer of proteins from polyacrylamide gels to nitrocellulose sheets: procedure and some applications. Proc. Natl. Acad. Sci. USA. 76:43504354.

37. Labarca, C., and K. Paigen. 1980. A simple, rapid and sensitive DNA assay procedure. Anal. Biochem. 102:344-352.

38. Bissell, D. M., L. E. Hammaker, and U. A. Meyer. 1973. Parenchymal cells from adult rat liver in nonproliferating monolayer culture. J. Cell Biol. 59:722-734.

39. Guguen-Guillouzo, C., and A. Guillouzo. 1983. Modulation of functional activities in cultured rat hepatocytes. Mol. Cell. Biochem. 53/ 54:35-56.

40. Bissell, D. M., S. Stamatoglou, M. Nermut, and C. Hughes. 1986. Interactions of rat hepatocytes with type IV collagen, fibronectin and laminin matrices. Distinct matrix-controlled modes of attachment and spreading. Eur. J. Cell. Biol. 40:72-78.

41. Yurchenco, P. D., E. C. Tsilibary, A. S. Charonis, and H. Furthmayr. 1986. Models for the self-assembly of basement membrane. $J$. Histochem. Cytochem. 34:93-102.

42. Laurie, G. W., C. P. Leblond, and G. R. Martin. 1982. Localization of type IV collagen, laminin, heparan sulfate proteoglycan, and fibronectin to the basal lamina of basement membranes. J. Cell Biol. 95:340-344.

43. Jeejeebhoy, K. N., J. H. Rajni, R. Mehra, and A. Bruce-Robertson. 1979. Hepatotrophic effects of insulin on glucose, glycogen, and adenine nucleotides in hepatocytes isolated from fasted adult rats. Gastroenterology. 78:556-570. 
44. Landry, J., D. Bernier, C. Ouellet, R. Goyette, and N. Marceau. 1985. Spheroidal aggregate culture of rat liver cells: histiotypic reorganization, biomatrix deposition, and maintenance of functional activities. J. Cell Biol. 101:914-923.

45. Michalopoulos, G., C. A. Sattler, G. L. Sattler, and H. C. Pitot. 1976. Cytochrome P-450 induction by phenobarbital and 3-methylcholanthrene in primary cultures of hepatocytes. Science (Wash. DC). 193: 907-909.

46. Rojkind, M., Z. Gatmaitan, S. Mackensen, M. A. Giambrone, P. Ponce, and L. M. Reid. 1980. Connective tissue biomatrix: its isolation and utilization for long-term cultures of normal rat hepatocytes. J. Cell Biol. 87:255-263.

47. Guguen-Guillouzo, C., B. Clement, G. Baffet, C. Beaumont, E. Morel-Chaney, D. Glaise, and A. Guillouzo. 1983. Maintenance and reversibility of active albumin secretion by adult rat hepatocytes cocultured with another liver epithelial cell type. Exp. Cell Res. 143:4754.

48. Clement, B., C. Guguen-Guillouzo, J.-P. Campion, D. Glaise, M. Bourel, and A. Guillouzo. 1984. Long-term co-cultures of adult human hepatocytes with rat liver epithelial cells: modulation of albumin secretion and accumulation of extracellular material. Hepatology. 4:373380 .

49. Terranova, V. P., D. H. Rohrbach, and G. R. Martin. 1980. Role of laminin in the attachment of PAM 212 (epithelial) cells to basement membrane collagen. Cell. 22:719-726.

50. Rubin, K., S. Johansson, I. Petterson, C. Ocklind, B. Obrink and M. Hook. 1979. Attachment of rat hepatocytes to collagen and fibronectin: a study using antibodies directed against cell surface components. Biochem. Biophys. Res. Commun. 91:86-94.
51. Johansson, S., and M. Hook. 1984. Substrate adhesion of rat hepatocytes: on the mechanism of attachment to fibronectin. J. Cell Biol. 98:810-817.

52. Rubin, K., M. Hook, B. Obrink, and R. Timpl. 1981. Substrate adhesion of rat hepatocytes: mechanism of attachment to collagen substrates. Cell. 24:463-470.

53. Carlin, B., R. Jaffe, B. Bender, and A. E. Chung. 1981. Entactin, a novel basal lamina-associated sulfated glycoprotein. J. Biol. Chem. 256:5209-5214.

54. Yurchenco, P. D., E. S. Tsilibary, A. S. Charonis, and H. Furthmayr. 1985. Laminin polymerization in vitro: evidence for a two-step assembly with domain specificity. J. Biol. Chem. 260:7636-7644.

55. Yurchenco, P. D., and H. Furthmayr. 1984. Self-assembly of basement membrane collagen. Biochemistry. 23:1839-1850.

56. Charonis, A. S., E. C. Tsilibary, P. D. Yurchenco, and H. Furthmayr. 1985. Binding of laminin to type IV collagen: a morphological study. J. Cell Biol. 100:1848-1853.

57. Woodley, D. T., C. N. Rao, J. R. Hassell, L. A. Liotta, G. R. Martin, and H. K. Kleinman. 1983. Interactions of basement membrane components. Biochim. Biophys. Acta. 761:278-283.

58. Popper, H., and S. Udenfriend. 1970. Hepatic fibrosis. Correlation of biochemical and morphologic investigations. Am. J. Med. 49:707721.

59. Orrego, H., A. Medline, L. M. Blendis, J. G. Rankin, and D. A. Kreaden. 1979. Collagenisation of the Disse space in alcoholic liver disease. Gut. 20:673-679.

60. Lowry, O. H., N. J. Rosebrough, A. L. Farr, and R. J. Randall. 1951. Protein measurement with the folin phenol reagent. J. Biol. Chem. 193:265-275. 